\title{
A institucionalización da violencia sexual na transición á democracia
}

\author{
The institunalization of sexual violence in transition to democracy
}

\author{
ENYA ANTELO ALVITE \\ Doutoranda en Historia Contemporánea na Universidade de Santiago de Compostela \\ Correo electrónico: enya.ant@gmail.com \\ Número ORCID: 0000-0002-7090-9856
}

\begin{abstract}
RESUMo
No presente artigo faise unha aproximación á institucionalización da violencia sexual e sexuada durante a etapa da Transición á democracia, centrándonos principalmente na década dos 80 por ser o momento en que se institucionaliza o Feminismo a través das novas leis e políticas públicas. A análise das mudanzas no plano lexislativo quere ser contrastada co que acontece a nivel práctico, mediante a presentación dunha serie de casos e sentencias que poñen sobre a mesa a fractura existente entre a realidade formal e material dun tempo que se alonga ata a actualidade.
\end{abstract}

Palabras chave: Violencia Institucional, Violencia de xénero, Feminismo, Transición.

\begin{abstract}
In this article, we approached the institutionalization of sexual and gender violence during the transition to Spanish democracy, focusing mainly on the decade of the 80s at the moment when feminism is institutionalized through the new laws and public policies. The analysis of the changes in the legislative plan are contrasted with what happens at a practical level, by presenting a series of cases and sentences that show the existing fracture between the formal and material reality of a time that last until today.
\end{abstract}

Keywords: Institutional Violence, Gender Violence, Feminism, Transition.

\section{INTRODUCIÓN}

Na actualidade vivimos tempos de certa axitación política e social que parecen querer lembrar a relación entre Historia e presente. Presente que non sempre avanza en liña recta, ameazando cun panorama político aparentemente en retroceso conxugado cun espertar social que semella masificarse na medida en que os riscos se fan máis palpables. 
Resulta complexo discernir o xeito en que cada un destes axentes alimenta ó outro, mais a posta en contacto das investigacións sobre o xurdimento dos Movementos Sociais deu como resultado interesantes perspectivas comparadas que tenden a establecer, grosso modo, tres factores chave; a saber, estrutura da oportunidade, estruturas de mobilización e procesos enmarcadores.

Co fin de axudar a comprender o funcionamento dos mesmos, traemos a colación as reflexións de McAdam, McCarthy e Zald entorno a sendos conceptos:

"La unión de estos dos elementos [estructuras de la oportunidad y estructuras de movilización] resulta insuficiente para explicar el fenómeno de acción colectiva. Existe un elemento mediador entre oportunidad, organización y acción; a saber, los significados compartidos y conceptos por medio de los cuales la gente tiende a definir su situación. Resulta imprescindible que las personas se sientan agraviadas por una situación determinada y crean que la acción colectiva puede contribuir a solucionar esa situación" (McAdam, McCarthy e Zald, 1999:26).

Seguindo tales preceptos, semella que o tempo presente resulta nun caldo de cultivo propicio para o espertar duns movementos que o pasado século bautizaba como Novos Movementos Sociais. Na súa praxe, ocupa un lugar particular o Feminismo, que ó longo do último ano veu medrar os seus apoios a gran velocidade, prometendo converterse no Movemento Social do noso tempo, ó que quizais se sumen outros, como pode ser o ecoloxismo -chegando incluso a converxer ${ }^{1}$. . Basta con rememorar os episodios do 8 de Marzo do actual e do pasado ano, xunto co espertar da opinión pública e o xurdimento de novas pensadoras e divulgadoras a través das redes sociais (Sádaba e Barranquero, 2019), para dilucidar o impulso e a popularidade que o Feminismo está sendo quen de acadar.

Certo é que o seu espallamento chama a unha pluralidade que de xeito máis evidente ca nunca converte ó Feminismo en Feminismos, poñendo no punto de mira a aquel catalogado como liberal, ollado con reticencia ante as súas -cuestionadas-capacidades para propiciar unha modificación do sistema. É sinalado e acusado de formar parte dunha estratexia a modo de contraofensiva por parte do propio sistema patriarcal dominante, obrigado a incluír na axenda política uns reclamos públicos fortemente apoiados. Unha liña na que se teñen posicionado recoñecidas voces como a de Ana de Miguel, Amelia Tiganus, Rosa Cobo, Beatriz Gimeno ou Nancy Fraser (entre moitas outras).

Neste sentido, xa cara finais dos anos oitenta, a revista feminista galega Area (1989, 4) apuntaba que "os sistemas que ostentan o poder optaron sempre por tentar asimilar as loitas que supuñan unha grave discordancia coa súa estrutura e que o povo asumía como

1 O encontro entre movemento feminista e o ecoloxista non é nin moito menos novidoso: xa nos albores do pasado século comezaba a introducirse por recoñecidas estudosas e activistas como Vandana Shiva (1989) ou Mary Daly (1990), que bebían, á súa vez, de teorías como as plantexadas en Le deuxième sexe (Beauvoir, S. 1949). Na actualidade son cada vez máis os estudos arredor do ecofeminismo, destacando nomes como o de Alicia Puleo, Petra Kelly, María Mies, Greta Gaard, Lynn Staeheli, Linda Peake ou Robert Booth, entre outras. 
proprias (...) dispostos a facer pequenas concesións antes que perdelo todo", poñendo así sobre a mesa a desconformidade existente coas concesións que dende o Estado Español se estaban a facer ás reivindicacións feministas do seu tempo.

Este tempo será o que aquí nos ocupe, nunha tentativa de facer ó longo deste artigo unha primeira aproximación ós reclamos feitos dende o Movemento Feminista na etapa da Transición á democracia, e á contestación dos mesmos por parte do aparello estatal, partindo da hipótese de que existe unha insuficiente asimilación destes a causa dunhas elites de poder máis interesadas na construción dunha imaxe democrática que na súa edificación formal. Esta análise, que pretende sumarse á recente liña de estudos do período transitorio dende a mirada escéptica cara o seu compoñente pacífico e modélico, forma parte dunha tese doutoral aínda en proceso de elaboración, que toma ó Movemento Feminista como paradigma do uso dos movementos populares e os seus reclamos na construción dun ideal democrático ${ }^{2}$. Unha investigación na que o contraste entre os cambios a nivel formal e material funciona como clave de bóveda á hora de cuestionar a intencionalidade de ruptura co sistema anterior. Deste xeito, a violencia institucionalizada contra as mulleres, tanto a nivel lexislativo como xudicial, funciona como ferramenta demostrativa da hipótese, xunto con outras que non serán aquí tratadas (sistema educativo, laboral, medios de comunicación de masas, ou mulleres en política, entre outros) por cuestións de espazo e temática. Centrarémonos, pois, na análise de casos concretos de violencia sexual e sexuada ó longo dos anos 80 -por ser o momento de institucionalización do Movemento Feminista na etapa da Transición- e o seu tratamento dende un aparello xudicial que, amparado pola timorata lexislación en materia de xénero, perpetra e reproduce condutas propias do pasado ditatorial.

Funcionan como elemento principal de coñecemento destes casos as fontes provintes dos colectivos feministas da época, especialmente as hemerográficas -revistas e boletíns- por ser neste tipo de medios onde se tratan as cuestión relacionadas ca violencia de xénero con maior profundidade, rigorosidade e actitude crítica. De entre as mesmas cómpre destacar as seguintes: a revista Vindicación Feminista, publicada dende xullo de 1976 ata decembro de 1979 baixo a coordinación de Lidia Falcón e Carmen Arcade, marcando un fito nas publicacións relacionadas co Movemento Feminista e de liberación da muller durante os anos da Transición; o boletín La mujer y la lucha, vinculado ó Movemento Democrático de Mulleres (MDM), e cuxos contidos se centraron nas esixencias sociais comúns a homes e mulleres, como a represión, a amnistía ou os conflitos laborais; o boletín Area, conformado por once números publicados entre o 1987 e o 1993, inicialmente vinculado ó Bloque Nacionalista Galego, do que se desliga progresivamente a partir do

2 Esta liña de estudos máis críticos co proceso da Transición comeza a adquirir relevancia a partires do ano 2000, co 25 aniversario da Transición á democracia, momento no que algunhas estudosas poñen sobre a mesa a necesidade de revisar o carácter modélico do proceso, abandonando a análise globalmente positiva que primaba ata o momento. Neste senso, destacan publicacións como a de Xabier Casals (2016), Alfredo Grimaldos (2013), Raúl Zelik (2016), ou Sophie Baby (2018), entre outras. 
seu quinto número; A Festa da Palabra Silenciada, voceiro do feminismo independente galego (FIGA), publicado dende 1983 ata o 2013; e por último a Revista Andaina, editada en Santiago de Compostela dende 1983, sendo potenciada polas organizacións que deron en conformar a Coordinadora Nacional de Organizacións Feministas, favorecendo deste xeito unha gran pluralidade ideolóxica certamente representativa da amplitude e diversidade dentro do Feminismo galaico.

A estas fontes, súmanse aqueles estudos e análises elaborados dende o seo dun Feminismo moi activo na recompilación de datos sobre a situación das mulleres en diversos ámbitos. Tal é o caso da labor desenvolvida polo Instituto da Muller, a Coordinadora Estatal de Organizacións Feministas, os numerosos grupos xurdidos entorno ós espazos universitario e sindical, ou, dentro do panorama galego, a Asociación Galega da Muller (AGM) e o colectivo Feministas Independentes Galegas (FIGA).

Por todo elo, o presente artigo remata resultando non só nunha comparativa da realidade formal e material en materia de violencia, senón tamén nunha aproximación á comprensión da mesma dende as mentalidades coetáneas, tentando contrastar estes resultados co tratamento das mesmas cuestións nos medios de comunicación de masas. Así mesmo, nas próximas páxinas ponse de relevo a labor levada a cabo por un Feminismo que traballa, moitas das veces, aloxado das institucións de xeito máis ou menos intencionado.

\section{UNHA PEQUENA APROXIMACIÓN Á CONCEPTUALIZACIÓN DA VIOLENCIA INSTITUCIONAL}

Dicía Thomas Platt que "Las personas son dueñas de las palabras, por lo menos en un sentido muy obvio: pueden hacer $-\mathrm{y}$, con frecuencia, hacen- que signifiquen cosas muy distintas. Las palabras son un importante medio de edificar el mundo" (Platt, en Blair, 2009: 20). Estas verbas son froito dun contexto intelectual determinado, nuns anos nos que o pensamento e reflexión entorno á conceptualización da violencia se trasladan ó academicismo dun xeito case profuso. As décadas dos 80 e 90 foron tempo para a teorización arredor da violencia acaecida durante as dúas Guerras Mundiais e na Europa coetánea, sendo o seu significado obxecto de análise dende diversas ramas, con resultados diverxentes segundo as disciplinas, presupostos teóricos, ou obxectivos da investigación (Blair, 2009). Neste senso, establecer unha definición restrinxida para a violencia antóllase complexo e incluso simplista, por estar esta suxeita a unha análise necesariamente multifactorial. De calquera xeito, quíxose traer a colación a reflexión de Platt por considerala de interese sobre o obxecto de estudo, pois insta a pensar sobre a evolución do termo, ó tempo que advirte do poder das verbas e do uso das mesmas.

Así pois, a mudanza na significación social e política de termos como violencia de xénero non deixan de formar parte da estratexia de loita dun Movemento Feminista que foi quen de convertelo nun problema social, conseguindo un rexeitamento e visibilidade do problema no debate público que non é consecuencia natural dos procesos de moderni- 
zación das sociedades avanzadas, senón vitoria dos relatos feministas (Arriero, 2010:80). Nesta liña de conquistas revélase a introdución do concepto violencia institucional de xénero, referido á responsabilidade dos aparellos estatais no que respecta ás prácticas de violencia contra as mulleres, xa sexa por acción ou por omisión das mesmas. En palabras de Encarna Bodegón (2014: 133) “(...) el Estado puede ser un agente que comete formas de violencia de género institucionalizada, no sólo porque a través de sus agentes se realicen actos de violencias (...), sino también por la responsabilidad que tiene (...) en la prevención, sanción y erradicación de dichas violencias contra las mujeres".

Vaia por diante que no momento de escribir estas liñas non existe no Estado Español ningunha lei sobre xénero que recolla o termo violencia institucional, nin a nivel estatal nin autonómico ${ }^{3}$. Nembargantes, a nivel internacional xa se ten recoñecido formalmente a súa existencia en documentos como a Declaración sobre a eliminación da violencia contra a muller das Nacións Unidas (1993), na Convención de Belém do Pará (1996), ou, máis recentemente, no Convenio de Estambul (2011), este último ratificado polo Estado Español no ano 2014 (Gil, 2014:9-16). Neste senso, pese á ausencia de lexislación específica, si hai un compromiso á hora da súa erradicación, cuxa posta en práctica resulta obxecto de debate por considerarse insatisfeita ante episodios tales como o recente incumprimento do Pacto contra a Violencia de Xénero nos presupostos xerais do Estado o pasado ano $2018^{4}$.

Volvendo ós tres factores explicativos no xurdimento dos movementos sociais, cabe considerar que a mediaticidade que acompañou a procesos determinados (como as sentencias nos casos de Juana Rivas ou de La Manada) axudasen a reavivar unha consciencia social no que ás responsabilidades dos estados respecta, do mesmo xeito que o fixo o asasinato de Ana Orantes cara finais da década dos 90, considerado espita na loita por unha lexislación en defensa da muller en materia específica de violencia (dando como resultado a Lei Integral contra a Violencia de Xénero no ano 2004), evidenciando as obrigas dos axentes estatais en tanto que o debate público poñía en cuestión as decisións institucionais arredor deste caso (Montalbán, 2016:7).

Unha vez máis as palabras de Zald, McAdam e McCarthy arroxan luz sobre o xeito en que se cultivan e desenvolven estes procesos de mobilización, apoiando o anteriormente descrito, e aclarando a relevancia de episodios concretos que -ó popularizarse- desarraigan ós individuos do illamento e a desinformación, traducíndose neste caso nunha posta en valor da responsabilidade estatal entorno á violencia exercida contra as mulleres:

3 Como excepción, atopamos a Lei do Dereito das Mulleres a erradicar a Violencia Machista en Cataluña, que recolle amplamente as diferentes formas de violencia sobre as mulleres, achegándose ó plano institucional, aínda que sen mencionalo expresamente (Bernal, 2018).

4 O 28 de Setembro de 2017 firmábase o Pacto Estatal contra a Violencia de Xénero, mediante o cal se establecían unha serie de medidas orientadas a afrontar a violencia contra as mulleres. Así mesmo, prevíase destinar 200 millóns de euros (o 0,04\% do presuposto estatal) para tales fins durante o ano 2018. Posteriormente, o Partido Popular reducía esta cantidade a 80 millóns, o que suporía un $40 \%$ menos do plantexado inicialmente (Kohan, 2018). 
“(...) el error fundamental de atribución [es] la tendencia de la gente a explicar la situación en que se encuentra en función de deficiencias individuales, más que por medio de la atribución a deficiencias al sistema. (...) este fenómeno es más frecuente en sociedades que generan aislamiento que en aquellas que se promueven organizaciones. A falta de la información y la perspectiva (...) los individuos aislados tienen una marcada tendencia a explicar sus problemas recurriendo a defectos individuales más que del sistema. Solo cuando se atribuyen deficiencias al sistema se genera una base para la acción colectiva" (McAdam, McCarthy e Zald, 1999:31).

\section{LEXISLACIÓN E POLÍTICAS PÚBLICAS EN MATERIA DE VIOLENCIA SEXUAL E SEXUADA NA TRANSICIÓN}

O achegamento á violencia institucional con carácter de xénero na etapa da coñecida como Transición á democracia ten por obxectivo poñer sobre a mesa os límites das políticas públicas e as decisións dun aparello estatal que chaman a considerar a existencia dun continuísmo respecto da cultura e da sociedade franquista, permitindo o enraizamento dunha lacra social que, ante a ausencia dun tratamento adecuado consegue afincarse na idiosincrasia do sistema. Mais antes de introducirnos de cheo nesta etapa, cómpre lembrar que as mudanzas en clave de xénero comezan a producirse antes da morte do ditador, xa cara finais duns anos 50 que veñen acompañados do abandono do sistema autárquico en prol do establecemento de lazos económicos e militares cos EEUU ${ }^{5}$. Ligado a estes intereses prodúcese unha modificación na situación da muller, que é chamada a tomar parte dun mundo laboral que precisa da súa forza de traballo e da súa capacidade de consumo. Así o explica Aurora Morcillo (2015) en Ser Mujer en Tiempos de Franco, e así o xustificaban as mulleres da Sección Feminina de Falange na defensa dunha nova lexislación:

"La incorporación de la mujer al ejercicio de todas las profesiones se va haciendo cada día más necesaria (...) Precisamente ahora iniciamos un Plan de Desarrollo muy ambicioso (...) El papel de la mujer en este aspecto es esencial, no ya solo por justicia hacia ellas, sino porque, en un plazo muy breve, de su presencia profesional va a depender nuestro futuro (...) La mano de obra masculina no podrá hacer frente a todas las necesidades de empleo si no se ve ayudada cada vez más intensamente por la mujer (...) $[\mathrm{Su}]$ acceso a todos los puestos de trabajo y profesión es, por consiguiente, una verdadera necesidad nacional" (VV.AA., 1963:31-44).

"También la incorporación de la mujer a las tareas del producir genera un crecimiento de la renta nacional (...) Los mayores ingresos que el trabajo de la mujer reporta se contrarrestan, aunque solo en parte, por unos mayores gastos en el hogar, dado que el ama de casa, e incluso las hijas mayores, son personas activas dentro del hogar, y cuando poseen un puesto de trabajo fuera de él, tienden a adquirir bienes o servicios" (VV.AA., 1963:47).

5 Á altura do verán de 1959 establécese un acordo entre o goberno español e o estadounidense, bautizado como Plan Nacional de Estabilización Económica. 
Trátase, pois, de argumentos alonxados de calquera que puidese ser identificado como feminista, sendo o fin último a resposta a aquelo que catalogan como "necesidad nacional". A estas necesidades responde esa nova lexislación que lle permite á muller a saída parcial do espazo privado, sen o abandono das súas responsabilidades no mesmo ${ }^{6}$. Pese a todo, continuaba subxugada ó varón a través dunha licencia marital que se deroga en maio de 1975 coa reforma do Código Civil e de Comercio. Derrogación parcial, pois o marido seguiría a ter patria potestade sobre os fillos e capacidade para administrar os bens da esposa ata o ano 1981.

Nun plano máis específico sobor da violencia, cómpre destacar a eliminación do Código Penal do chamado uxoricidio por causa de honra á altura de 1963, aínda que de xeito máis teórico ca práctico, pois a cuestión da honra no matrimonio mantén a súa presenza nas mentalidades colectivas, e asuntos como a violencia de xénero dentro e fóra do fogar seguen a tratarse nos medios con naturalidade e ausencia de condena explícita. Exemplos disto atópanse en diversos artigos das revistas feministas anteriormente mencionadas, ou en estudos que recollen algunhas das novas publicadas en recoñecidos xornais e revistas da época, tales como Interviú, ABC, La Hoja del Lunes ou Por Favor (Larumbe, 2004). Nesta mesma liña, é de obrigada mención o filme de José María Forqué, Pecados Conyugales (1968), que deixa constancia nun aparello cinematográfico de gran valor como fonte histórica da despreocupación social e os baleiros legais ós que permanece ligada a violencia contra as mulleres.

A partires de aquí, non hai máis reformas ata os anos da Transición, concretamente en xuño de 1983 coa reforma do Código Penal (uns seis meses despois da chegada ó poder do PSOE).

No debate constitucional este tema non chegou a introducirse, e, de feito, alzáronse voces en contra da responsabilidade que debían asumir os poderes públicos en prol da igualdade: Antonio Carro, Gonzalo Fernández de la Mora e Laureano López Rodó propuxeron a eliminación do compromiso dos poderes públicos na promoción da igualdade entre a cidadanía, apelando que non era esta materia constitucional, tal e como evidencia a lectura dos debates parlamentarios, recollidos parcialmente por Begoña San José (1989). Finalmente, dito compromiso queda establecido no artigo 9.2, o que permite a posterior posta en marcha de reformas e políticas públicas -se ben de efectividade cuestionable- orientadas a paliar a desigualdade entre os sexos pola que dende a rúa clamaba un Movemento Feminista moi activo durante toda a segunda metade dos setenta.

A tales reclamos responde esa primeira modificación do Código Penal, fortemente criticada polo seu carácter timorato. Unha reforma orientada unicamente ós casos de violencia sexual, sendo inexistente lexislación específica para os casos de violencia sobre

6 Referímonos á Lei 56/1961 de Dereitos políticos, profesionais e de traballo da muller, pola cal se ampliaban os empregos e carreiras universitarias ás que esta podía acceder (con restricións), ó tempo que se abría a porta á posibilidade de traballar sen o consentimento do marido (aínda que, no caso de darse unha negativa por parte do mesmo, ambos conxugues deberían concurrir a xuízo). 
a muller doutro carácter, como pode ser a física ou psicolóxica, pese a contar ambas modalidades cun amplo número de denuncias (Gráfico 1). Para isto, haberá que agardar ó ano $2004^{7}$.

\section{GRÁFICO 1}

Denuncias por malos tratos no Estado Español. 1985-1988. Fonte: Elaboración propia a partir dos datos recollidos pola Comisión de Relacións do Defensor do Pobo e dos Dereitos Humanos. Visto en CFG/Carp. 017

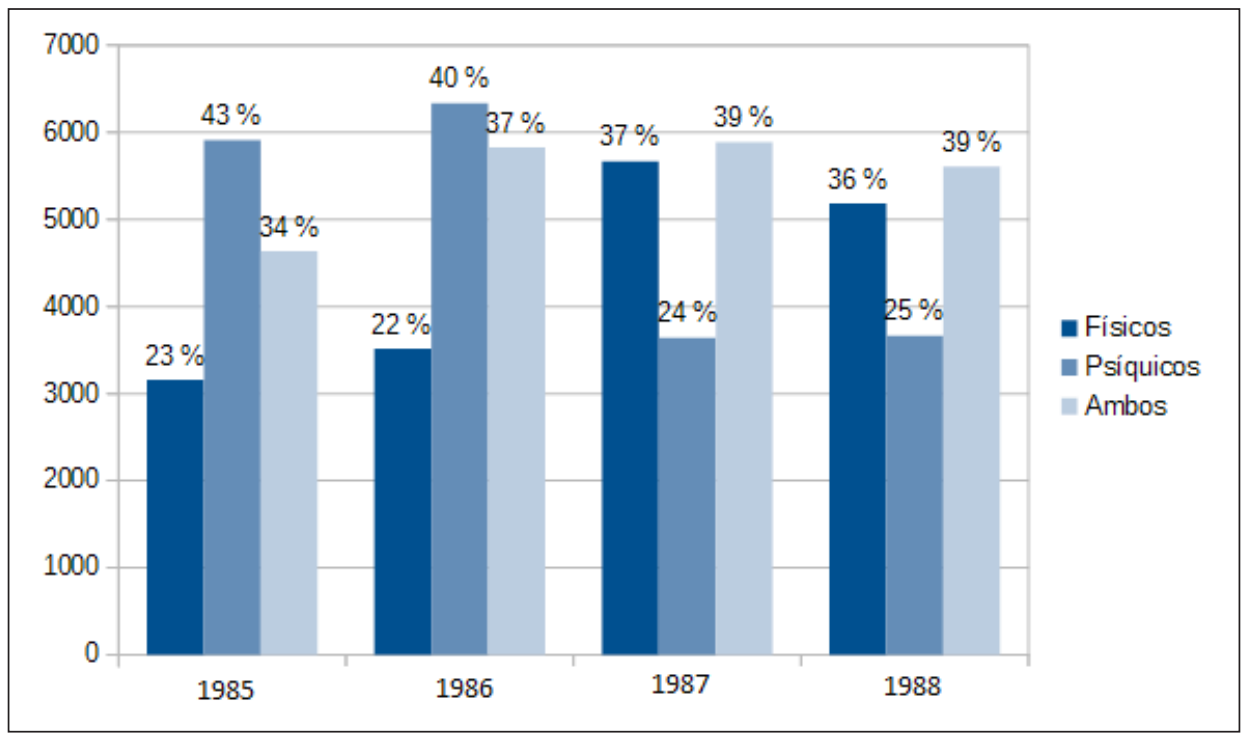

Así pois, en materia de violacións e agresións sexuais -contempladas no título noveno- eliminábase o perdón da ofendida e a dote que o violador debía entregar á agredida en caso de ser viúva ou solteira, mudándoa por unha indemnización ao marxe do estado civil da mesma. Aparte disto, non existen modificacións respecto do Código Penal franquista, conservándose o termo delitos contra a honestidade, e considerando como violación unicamente os casos de penetración vaxinal con forza ou ameazas. Os demais casos eran definidos como abusos deshonestos, nos que o perdón da vítima continuaba vixente (igual que para os casos de estupro ${ }^{8}$ ), permitindo así a desaparición do delito se se presentaba antes da sentenza. Tal e como veremos no apartado próximo - no que se analizan unha serie de casos concretos a modo de exemplo do aquí descrito - isto permitirá a existencia de subornos e coaccións ás vítimas, así como o ditame de sentencias arbitra-

7 Momento no que se aproba a Lei Orgánica de Medidas de Protección Integral conta a Violencia de Xénero.

8 Aqueles casos nos que o violador dunha muller menor de idade (menos de 18 anos) era o seu pai, irmán, titor, familiar, mestre, xefe, ou superior laboral. 
rias orquestradas por un corpo xudicial non depurado, que continúa a perpetrar condutas propias do pasado ditatorial. Do mesmo xeito, para que un violador ou calquera agresor sexual puidese ser condenado, a denuncia debía ser presentada pola "persoa agraviada" ou "o seu ascendente, representante legal ou gardador de feito", algo que non acontece con calquera outro delito no que non resulta obrigatorio que a denunciante sexa a vítima9. Todo isto permite - xunto con outros factores- que unha boa parte das denuncias presentadas, así como dos procedementos iniciados por este tipo de delitos, non chegasen nunca á preparación para o xuízo ${ }^{10}$.

A segunda modificación do Código Penal non chegará ata os albores da nova década. Á altura de 1990 o goberno do PSOE pratexaba ante o Congreso dos Deputados unha serie de mudanzas respecto do anteriormente citado: o termo delitos conta a honestidade muda polo de violación e abusos sexuais, mais a violación continúa a considerarse unicamente en casos de penetración vaxinal, pese a aparecer un novo delito denominado acceso carnal -menos penado que a violación vaxinal- que incluía a violación anal. Doutro bando, o termo abusos deshonestos pasa a denominarse como abusos sexuais. Todo o demais continúa inmutable, permanecendo o perdón da ofendida e e a obrigatoriedade de presentar denuncia pola propia vítima para que esta sexa efectiva ${ }^{11}$.

No tocante ás políticas públicas atopámonos cun considerable atraso respecto ó resto de países da Europa Occidental. Atraso comprensible se temos en conta que "las mujeres españolas conquistaron en solo diez años las reformas básicas legales que en otros países habían tardado más de cuarenta años" (Martínez, 1997:221). Neste punto, e pese á lóxica que se atopa nesta reflexión, quizais deberíamos considerar a mudanza do termo conquista polo de reconquista, pois esta visión non deixa de estar influenciada -consciente ou inconscientemente- por aquel relato da Transición modélica que tende a esquecer que algúns daqueles reclamos feitos no período transitorio estaban orientados a recuperar os dereitos perdidos tras o golpe de estado do 36 -como son os casos do divorcio ou o aborto-.

Sexa como for, a posta en marcha de políticas públicas dirixidas a paliar as desigualdades entre os sexos non chega ata entrados os anos 80, e faino da man dun Instituto da Muller que ven a representar a institucionalización do Movemento Feminista. Os reclamos do mesmo, xunto coa presión e a influenza internacional que implican para o Estado Español a incorporación á Comunidade Europea en 1986 permitirán a elaboración do Primeiro Plan para a Igualdade de Oportunidades á altura de 1987. No mesmo, incluíanse máis de 120 medidas agrupadas en seis áreas: igualdade e ordenamento xurídico, familia e protección social, educación e cultura, emprego e relacións laborais, saúde, e cooperación internacional e asociacionismo ${ }^{12}$. Unha iniciativa que non deixou de formar

$9 \quad$ Visto en CCG; CFG/ Carp 017.

10 Segundo a Coordinadora Feminista Galega, á altura de 1989, só un $25 \%$ dos casos chegaban a ser xulgados (Ibid.).

11 Ibid.

12 Visto en CCG/ I Plan de Igualdade. 
parte dunha estratexia política orientada a consolidar a democracia a través da pesquisa dunha igualdade que puido quedar nunha mera declaración de intencións, tal e como se considerou dende algúns frontes do chamado Feminismo Independente ${ }^{13}$. Ilustrativo disto resulta o fragmento que se presenta a continuación, parte dun artigo publicado na revista galega Andaina no que Nanina Santos reproba a labor do Instituto da Muller:

"O Instituto sitúase claramente nunha política de reformas, de parches, de cativas milloras (...). Claro... andamos neste tema nun nivel tan primario que calquera cousiña que se diga ou se faga xa parece o nova mais, a liberación en marcha (...). Se o Instituto fai unha campaña, por limitada e discutibel que sexa, contra os maus tratos e as violacións que a cotío sofrimos, hai xentes que pensan que é do máis avantado e novidoso. Pero, o que é demasiadísimo é que non haxa centros de información sexual abondo. É demasiadísimo que os que andan creando non sexan nin siquera eso, senón de planificación familiar, que o seu só nome xa o explica todo. (...) a este nivel de cousas, dúas ou tres reformas que o Instituto logre poñer en pé, vai aparecer aos ollos de muitas mulleres coma o camiño máis axeitado para a conquista das súas demandas. Porque educa ás mulleres ás que chega (financiando actos que precisan de medios que o Movemento Feminista escasamente dispón) na conformidade coa súa situación un chisco millorada, porque, según elas, segundo a filosofía política imperante, é a úneca posibel" (Andaina, $\left.\mathrm{N}^{\circ} 6,1984\right)$.

Estas verbas non son máis ca un exemplo da crítica da que foi obxecto o Feminismo Institucional, repetido noutros medios de diversos lugares do Estado. Nelas evidénciase a desconfianza cara unhas políticas públicas e institucións que veñen a considerarse simbólicas, meras estratexias de márketing para os gobernos, sen infraestruturas, recursos ou competencias suficientes. Bo exemplo disto son as constantes queixas por falta de financiamento feitas dende a prensa feminista, ou os testemuños que nos deixa a memoria oral sobre os problemas de acceso a infraestruturas de información en determinadas zonas do Estado (especialmente as rurais):

“(...) respecto dos Centros de Orientación Sexual, evidentemente non desfrutamos da súa asistencia in situ, xa que tamén nese caso teríamos que nos desprazar á urbe máis próxima. É aí onde está o problema: nos desprazamentos (...). Relacionado con isto eu aponto unha problemática que para min ten visos de misterio. Refírome á asistencia social. Aquí seica hai unha asistenta social, pero non se saben nen os días nen as horas nas que atende, e por non saber non sabemos nen quen é. O gracioso do asunto é que

13 Neste punto faise necesaria unha breve explicación da confrontación existente no seo do Movemento Feminista destes anos, dividido principalmente en dúas ramas: dun lado, o Feminismo Institucional, aquel que avoga pola dobre militancia das mulleres (tanto dentro dos partidos como do Movemento Feminista); doutro bando, o Feminismo Independente, reticente a entrar no xogo político e escéptico coa labor levada a cavo dende as institucións. Os desencontros entre ambos maniféstanse xa dende mediados dos 70, mais será á altura de 1979, durante as II Jornadas Estatales de la Mujer (celebradas en Granada) cando se evidencia a inminente ruptura. 
teño ouvido que ela se ten queixado da falta de clientela. Como ves, unha absoluta desorganización" (Testemuño de Araceli, en Revista Area, N² 2, 1987)

Do mesmo xeito, os datos e estadísticas elaborados dende os propios organismos institucionais semellan apoiar tales conxecturas en gran cantidade de ámbitos (acceso das mulleres á educación, mundo laboral, traballo doméstico, política, etc), máis cinguirémonos a aquelas relacionadas ca violencia de xénero: por exemplo, o número de Casas de Acollida ou Centros Asesores da Muller foron obxecto de crítica por considerarse insuficientes ${ }^{14}$, pese a existir un aumento das mesmas entre o 1988 e o 1989 (Gráficos 2 e 3), que aínda así non terían capacidade para respostar ás demandas se entramos en comparativas co número de denuncias das que queda constancia no Gráfico 1. Doutro bando, case dez anos despois de aprobada a Lei do Divorcio, continuaba a clamarse pola súa modificación en vistas á pouca axilización dos trámites, que, por custosos e duradeiros deixaban desprotexidas a un elevado número de mulleres vítimas de violencia de xénero dentro do fogar (segundo os datos provintes da Coordinadora Feminista Galega, das 98 mulleres asasinadas en 1987 polos seus maridos ou compañeiros, moitas delas estaban en trámite de separación $\left.{ }^{15}\right)$.

\section{GRÁFICO 2}

Número de casas de acollida e prazas en Galiza e no Estado Español. 1989. Fonte: Elaboración propia a partir dos datos recollidos pola Comisión de Relacións do Defensor do Pobo e dos Dereitos Humanos. Visto en CFG/ Carp. 017

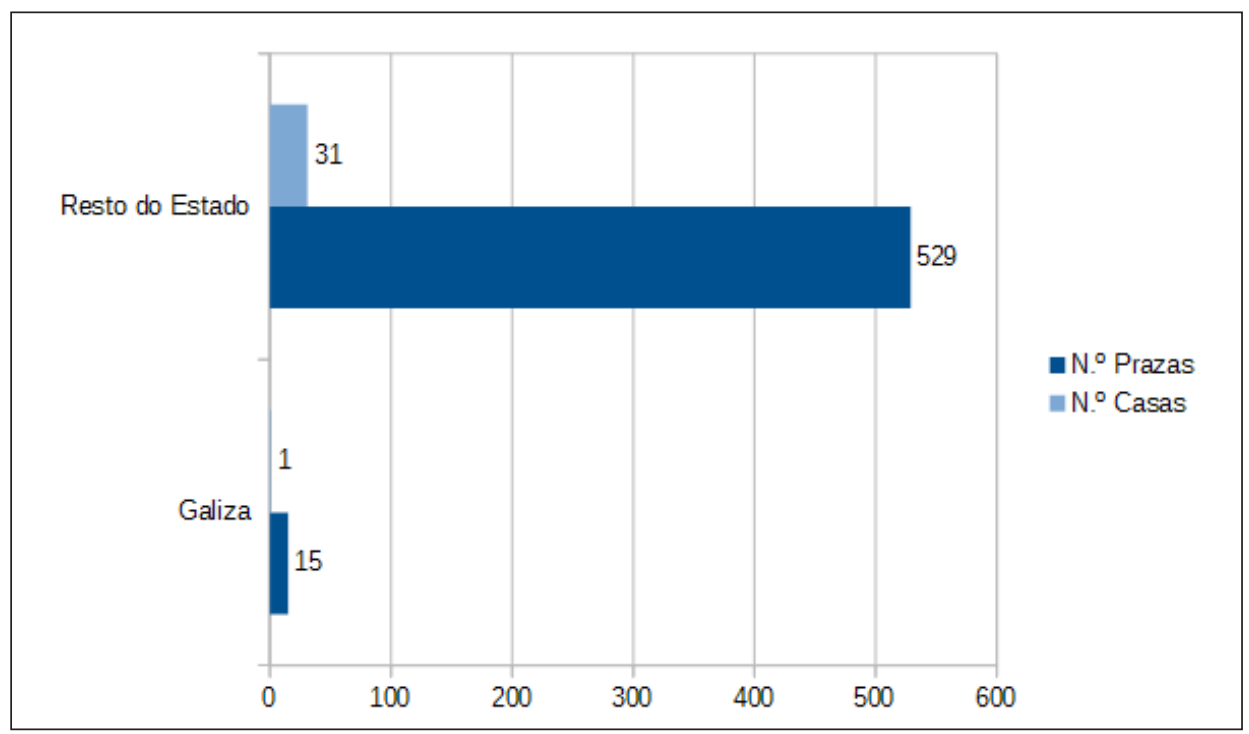

14 Visto en CCG; AL - AGM.

15 Visto en CCG; CFG/ Carp. 017. 


\section{GRÁFICO 3}

Evolución do número de Centros Asesores da Muller en Galiza e no Estado Español. 1988-1989. Fonte: Elaboración propia a partir dos datos recollidos pola Comisión de Relacións do Defensor do Pobo e dos Dereitos Humanos. Visto en CFG/Carp. 017

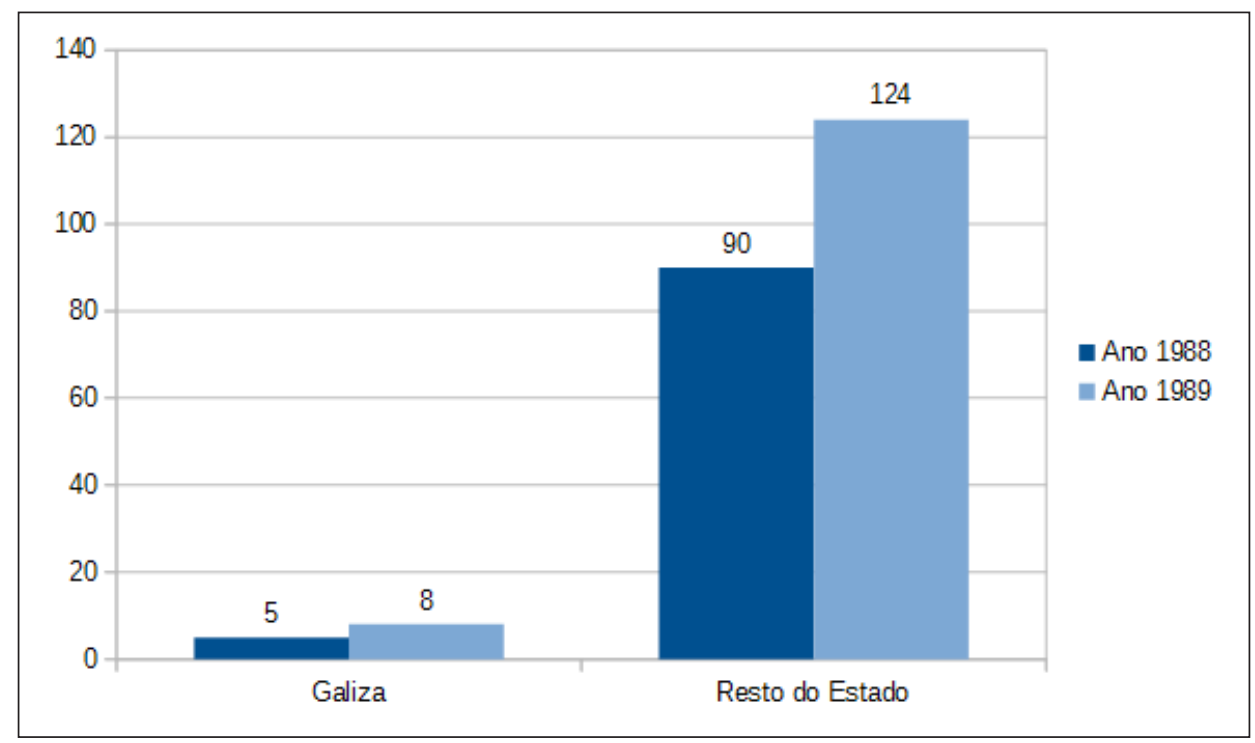

\section{SENTENZAS ARBITRARIAS E TRATAMENTO MEDIÁTICO}

Comentabamos ó inicio destas páxinas a importancia das fontes hemerográficas no recoñecemento da institucionalización da violencia sexual e sexuada durante a etapa transitoria. Neste punto, a labor das asociacións e grupos provintes do Feminismo Independente convértese nun papel chave pola constancia e profundidade ca que tratan temas relacionados cas violacións ou malos tratos, funcionando como un elemento de primeira orde á hora de coñecer eses casos e sentencias que veñen a institucionalizar a violencia de xénero, e cuxo rastrexo nos medios de comunicación de masas evidencia a subordinación destas ás elites de poder en múltiples ocasións. Unha subordinación que moitas das veces se converte en silencio. Silencio outras veces imposible ante a forza e o ruído dun Feminismo con suficiente capacidade mobilizadora como para forzar ó seu tratamento mediatico, de tal maneira que determinados episodios rematan adquirindo maior ou menor presenza nos medios de xeito proporcional ó calado social dos mesmos.

Serán eses casos máis coñecidos os que se expoñan nas seguintes liñas, moitos dos cales están recollidos nas memorias de Cristina Alberdi (2001), primeira muller no Consello Xeral de Poder Xudicial e Ministra de Asuntos Sociais na última lexislatura de Felipe González. Pese a ser obxecto de crítica por ter obviado temas de especial relevancia como a implicación da cúpula de poder na guerra sucia que marcou os anos da Transición, 
“(...) tema sobre el que corre un tupido velo con la escusa de la razón de Estado" (Cuartango, 2001), o certo é que El Poder es cosa de hombres remata resultando nunha fonte de gran interese para o achegamento a esa institucionalización da violencia:

"Fueron muchos los casos de jueces que llegaron a la mesa del consejo por sentencias en las que se vertían consideraciones vejatorias para las mujeres. Uno de los más famosos fue el de la 'minifalda'. Un empresario de Lérida fue multado por abusos deshonestos a una trabajadora. El juez (...) dijo para explicar una pena tan leve que 'la víctima, al parecer ataviada con una prenda corta, pudo provocar, si acaso inocentemente, al empresario'. Se alzaron muchas voces pidiendo un escarmiento contra el magistrado. No tuvimos éxito. (...) Otra sentencia, esta vez de la Audiencia Provincial de Pontevedra, absolvió a dos acusados de violación, argumentando que la víctima 'llevaba una vida licenciosa y desordenada, como revela que careciese de domicilio fijo y se encontrase sola en una discoteca a altas horas de la madrugada'. Y añadían, que fue lo que más escándalo suscitó, que 'al prestarse a viajar en coche con dos desconocidos se situaba en disposición de ser usada sexualmente en horas de la noche y en lugar solitario'. En el pleno del Consejo se llegó a debatir la posibilidad de presentar una acusación de prericación contra los magistrados (...). Finalmente, en aras de la exquisita prudencia con la que casi siempre actúa el Consejo en relación con los jueces -hagan lo que hagan- se desechó la idea" (Alberdi, C. 2001:63)

Estes casos que Alberdi destapa a comezos do novo século nunha sorte de tardío desencanto, eran xa divulgados dende o Feminismo Independente nos seus anos coetáneos. Os boletíns e revistas feministas máis populares da época adicaron boa parte dos seus esforzos a facer pública a violencia contra as mulleres, tema que, ata mediados dos anos 70 resulta controvertido incluso dentro do propio movemento de liberación da muller; por exemplo, o boletín La Mujer y la Lucha, en activo dende o 1968, introduciu o tema con especial cautela, falando exclusivamente da violencia que exercían as institucións franquistas sobre a muller, quizais por medo ó rexeitamento dos compañeiros de partido ou das propias mulleres militantes. Nembargantes, na medida en que avanza a década dos 70, e sobre todo ó compás da chegada de obras como a de Kate Millet ou Erin Pizzey, comezan a desenvolverse novas ferramentas para analizar a violencia dende outras perspectivas (Arriero, 2010).

Neste senso xoga un papel esencial a revista Vindicación Feminista. Na análise dos seus trinta números atopamos múltiples mencións á violencia contra as mulleres, chegando a facer chamamentos ás súas lectoras para que visibilizasen a través de Vindicación todos os casos dos que tivesen constancia:

“(...) publicamos con el fin de recoger y difundir todas las denuncias de violaciones que se nos comuniquen, en un esfuerzo común inaplazable. Esfuerzo que debemos emprender todas las mujeres y todos los movimientos de mujeres para llevar a cabo una campaña en todo el país contra la más abyecta agresión infringida por los hombres al otro sexo" (Vindicación Feminista, N. ${ }^{\circ}$ 15, Setembro 1977) 
Dende o órgano coordinado por Lidia Falcón déuselle tamén voz ás agresións sufridas por mulleres nas comisarías e cárceres, unha liña de traballo que tamén sigue a revista Area. Queremos destacar aquí os casos de Rosario Cabrera, Jimena Alonso, Susana Lópes e Pilar Casanova, pois vimos a considerar que a través dos mesmos queda constancia da perpetración dun modus operandi propio das Forzas de Orde franquistas -á semellanza dos relatos recollidos en La noche y la niebla: mujeres en las cárceles franquistas (Doña, 1978) - con condutas asociadas a sociedades ditatoriais ou somerxidas en episodios violentos (Nash e Tavera, 2003), empregando torturas cun carácter específico de xénero:

"El 14 de Agosto (...) en Las Palmas de Gran Canaria era detenida Rosario Cabrera Batista, de 18 años, la hermana del ya famoso, supuesto autor del secuestro del industrial Eufemiano Fuentes. (...) Rosario se encontraba en los calabozos de la comisaría cuando (...) el inspector de policía José Manuel Carballo García hizo que la condujeran a su despacho. Allí (...) le indicó que iba a salir a la calle en su compañía (...) El atento funcionario le [explicó] la conveniencia de prestarle sus favores de lo que se deduciría un mejor trato para su familia. Literalmente coaccionada (...) Rosario se vió en el domicilio de Carballo, donde (...) consumó la violación" (Vindicación Feminista, N. ${ }^{\circ}$ 5, Novembro 1976)

"A tortura nas comissarias de policia ou nos quarteis da guardia civil som práctica qüotidiana no Estado Espanhol (...). Lembámo - nos daquela muller á que durante um interrogatório lhe introduziram um pau de vassoira na vagina; aqueloutra á que peliscavan os peçons; á que obrigarom a chupar o ‘tampax’usado; (...) ás que lle fixeron adoptar vejatorias posturas; aquelas ás que lhe chamavan putas" (Area, N. ${ }^{\circ}$, Xullo 1988)

Do mesmo xeito, as declaracións de Jimena Alonso sobre as torturas e ameazas de violación ás súas fillas, son outra proba máis do uso de mecanismos de presión con carácter sexuado. A estes casos súmanse os de Susana e Pilar, detidas a raíz da súa relación sentimental con presuntos integrantes do Exército Guerrilleiro do Povo Galego Ceive, sendo a segunda posta en liberdade por falta de probas. Nos catro procesos as mulleres detidas contan con vínculos con personaxes masculinos de maior interese para os Corpos de Seguridade que as propias presas, podendo funcionar a violencia exercida sobre as mesmas como un mecanismo de presión e humillación non só da propia vítima, senón tamén do "inimigo" en xeral, ou dos acusados en particular ${ }^{16}$. Igual ca na Guerra, igual ca na ditadura, a violación e a tortura sobre a muller continúa a ser unha forma de demostrar poder, superioridade sobre o inimigo, sobre a "muller do inimigo".

Noutra orde de cousas, e achegándonos ó panorama galaico, continuamos coa análise duns anos 80 que a revista Vindicación xa non cubre. Tomamos como elemento de

16 Nos casos de Jimena Alonso, Susana Lópes e Pilar Casanova a súa detención está relacionada co vínculo que cada unha delas mantiña con homes acusados de formar parte de grupos terroristas. Pola súa parte, Rosario Cabrera é arrestada a raíz do delito cometido polo seu irmán, inculpado por ser autor dun secuestro. 
referencia o boletín Andaina, vinculado á Coordinadora Nacional de Organizacións Feministas e publicado dende 1983 ata a actualidade. A súa estrutura non difire en exceso da revista madrileña -alomenos na súa primeira etapa- existindo, igual que nesta, un apartado de denuncias orientado a dar a coñecer en todos os seus números os casos de violación e violencia dos que tivesen constancia. Ademais de recoller os casos xa mencionados nas memorias de Alberdi, fan eco doutros que non se atoparon no escrutinio doutras revistas e xornais. Destacan aquí os de Carme López Barral, agredida en Sada en Xaneiro de 1985 pola Garda Civil tras presentar unha denuncia por maltrato doméstico ${ }^{17}$, e o das traballadoras da TVG, que en Maio do 86 denunciaban a través de Andaina o acoso sexual exercido sobre as traballadoras da radio galega por parte de Xosé Luís Blanco Campaña, presidente da cadea ${ }^{18}$. En ambos casos, a actitude dos medios de comunicación é a mesma: silencio e escurecemento en favor das elites de poder.

Onde ese silencio non foi posible foi para o caso de Genma Moure. O activismo social que o acompañou non o permitiu, ó que quizais debamos sumar as pugnas políticas polo poder como elemento chave na súa mediatización. A agresión sexual perpetrada por dous policías municipais no Depósito Municipal de Compostela en 1982 apareceu reiteradas veces na prensa grazas ó barullo creado por un feminismo organizado que chegou a irromper nos plenos municipais para forzar a axilización dunha sentenza que se demorou máis de dous anos ${ }^{19}$. A esquerda política galaica apoiou os reclamos dun xuízo público, xunto ca expulsión dos dous violadores do corpo policial. O alcalde da cidade (Marcial Castro, de Unión de Centro Democrático) chegou a ser acusado por Esquerda Galega e o Bloque Nacionalista Galego de dificultar o esclarecemento do caso ${ }^{20}$, así como de reprimir actos e manifestacións coa retirada de cartaces e a detención de ata catro activistas. Así mesmo, a Asociación Galega da Muller denunciou en varias ocasións os intentos de suborno á vítima para que esta presentase o xa citado perdón da ofendida ${ }^{21}$. Finalmente, a resolución do caso deixa constancia do amparo e protección por parte do sistema xudicial ás Forzas e Corpos de Seguridade do Estado, que non chegaron en ningún caso a cumprir a sentencia ditada, tal e como queda constancia no $\mathrm{N}^{\circ} 7$ da revista Andaina $(1985,7)$. Algo semellante acontece no Xulgado de Instrución de Badalona en 1989, o cal denegou o procesamento dun policía acusado de violación en base a "no acreditarse el acceso carnal completo, elemento típico del delito de violación" ${ }_{22}$.

Estes e outros casos quedan recollidos nesa prensa feminista que traballou en prol de sensibilizar sobre a presenza do machismo a todas as esferas. Mais ben é certo que tamén algúns organismos máis achegados ás institucións -ou directamente ligados ás

17 Revista Andaina, 1985, 7

18 Revista Andaina, 1986, 10

19 Visto en AGMSC/ Carp. 063

20 Visto en AGMSC/ Carp. 077

21 Visto en ASM - VV/ Carp. 04 e AGMSC/ Carp. 80

22 Visto en CCG, CFG. Carp. 2/017 
mesmas- conseguiron poñer sobre a mesa o machismo enquistado nese aparello xudicial co que aquí se quere evidenciar unha das ramas a través das cales se institucionaliza a violencia contra as mulleres. O exemplo máis claro é o caso da Coordinadora Estatal de Mulleres Avogadas, que veu a desenvolver unha ardua actividade na visibilización dos casos de desigualdade e de comportamentos machistas no seo do corpo xudicial ou ante a propia lei. No seu primeiro congreso, celebrado en Barcelona á altura de 1987, denunciábanse cuestións como a impunidade total nos casos de violación conxugal, a pasividade do Ministerio Fiscal en canto á persecución destes delitos, a existencia de trato privilexiado para os encadeados por violación, ou o seguimento de diferentes criterios na valoración das probas para os delitos de agresión sexual. Así mesmo, revelaban a presenza de abusos e agresións dentro do ámbito de traballo, e a falta de denuncia dos mesmos por medo á perda de emprego ${ }^{23}$.

Pese a todo, as súas capacidades para mudar o funcionamento interno do sistema semellan practicamente nulas, en vistas ás xa citadas palabras da avogada Cristina Alberdi en referencia á falta de actuación do Consello en relación ós xuíces, ata tal punto que non se atopou para o período estudado ningunha condena a un xuíz por delito de prevaricación. Isto, xunto con esa pasividade do Consello Xeral do Poder Xudicial ó aplicar o réxime sancionador levaría á total impunidade e á libre circulación de sentenzas, condutas e mentalidades machistas que enraízan no tempo ate os nosos días.

\section{CONCLUSIÓNS}

Ó longo das páxinas precedentes tentouse evidenciar o xeito no que a violencia contra as mulleres se institucionaliza no discorrer dun tempo que quixo presentársenos como o do cambio e as mudanzas cara un novo sistema. A análise de casos concretos, tanto en canto á actuación do aparello estatal ante as denuncias de violencia ou violación, como a propia implicación de axentes estatais na perpetracion directa da mesma, pon sobre a mesa a existencia de condutas que, lonxe de tratarse de casos illados, invitan a reflexionar sobre a autenticidade e efectividade do proceso transitorio, demostrando a supervivencia e o continuísmo do réxime anterior (alomenos nalgunhas esferas).

O estudo da nova lexislación en materia específica de violencia, en contraste coas críticas que esta recibe dende o seo do Movemento Feminista, arroxan luz sobre a existencia de grandes deficiencias que aumentan na medida en que se analiza a súa posta en práctica. Nun plano formal, as novas leis son insuficientes en canto a acadar o compromiso de cara á igualdade establecido no documento constitucional, mais o problema aumenta ó examinar a súa posta en práctica, sobre a cal os datos cuantitativos demostran unha persistencia na situación de subordinación do colectivo feminino. Bo exemplo disto seria

23 Visto en http://www.cemabog.org/index.php?option=com_content\&view=article\&id=4:i-congreso-barc elona\&catid=2: anteriores \&Itemid $=5$ 
a escaseza de infraestruturas, a falta de financiamento, as problemáticas derivadas da lei do divorcio ou do aborto, ou o fallo de moitas das sentenzas en materia de violación ou violencia contra a muller e a impermeabilidade do aparello xudicial, sendo preciso facer especial fincapé naqueles nos que os acusados do delito se tratan de axentes estatais. A todo o anterior súmase o silencio adoptado en múltiples ocasións por parte dos medios de comunicación de masas, do que xorden novas cuestións entorno á posible existencia dun escurecemento informativo pouco apropiado na construción dun sistema democrático, así como do papel xogado pola prensa durante a etapa transitoria.

Compréndese deste xeito a tendencia dese feminismo catalogado como independente a valorar as actuacións e promesas feitas dende os partidos políticos do momento como estratexias de márketing, entendendo que as súas propostas respondían máis á intención de conseguir o voto feminino que a mellorar a situación das mulleres.

Todo isto leva a considerar o feito de que os avances en materia de xénero producidos durante a Transición á democracia responderon a unha sorte de condutas vantaxistas e interesadas, orientadas a paliar toda unha serie de presións -internas e externas- que esixían ó réxime español un lavado de cara. Neste sentido, reflíctese ese uso dos reclamos feministas por parte das elites de poder, favorecendo a existencia de discordancias internas que rematan por dinamitar o movemento ó acoller unicamente aquelas propostas e reivindicacións máis asumibles, por non implicar unha verdadeira reconstrución do sistema na súa totalidade.

Faise preciso analizar en maior profundidade a labor desenvolvida dende un movemento internamente confrontado, que axude a comprender as herdanzas e influenzas do Feminismo actual. Doutro bando, cómpre tamén ampliar, a todas luces, o presentado nas páxinas precedentes, analizando unha maior cantidade de casos que poidan aportar unha mostra superior, máis representativa da realidade estudada, pese a que se considera que os aquí expostos axudan a establecer unha primeira aproximación á institucionalización dunha violencia que pon en tela de xuízo a edificación dun réxime democrático e igualitario, ca consecuente herdanza das súas deficiencias no sistema actual. 


\section{BIBLIOGRAFÍA}

Alberdi, C. (2001): El poder es cosa de hombres: Memorias Políticas. La Esfera de los Libros, Madrid.

Arriero, F. (2010): “Cuando todos callaban: discurso y acción del Movimiento Feminista contra la violencia de género durante la Transición”, en VVAA (eds.), Violencia y género. Seminario de estudios de la mujer, Amarú Ediciones, Salamanca, 79-112.

Baby, S. (2018): El mito de la Transición pacífica. Violencia y política en España (19751982). Akal, Madrid.

Bernal, A. (2018): "La violencia institucional, la gran impune en la violencia de género", Público. Recuperado de https://www.publico.es/sociedad/feminismo-violencia-institucional-gran-impune-violencia-genero.html.

Blair Trujillo, E. (2009): “Aproximación teórica al concepto de violencia: avatares de una definición”, Política y Cultura, 32, 9-33.

Bodegón, E. (2014): "Violencia institucional y violencia de género", Anales de la cátedra Francisco Suárez, 45, 131-155.

Casals, X. (2016): La Transición española. El voto ignorado de las armas. Pasado \& Presente, Barcelona. https://doi.org/10.1387/hc.17955

Colanzi, I. (2015): “(Per)versiones del patriarcado: mujeres y violencia institucional”, Derecho y Ciencias Sociales (Violencias), 12, 8-32.

Cuartango, P. (2001): “El poder es cosa de hombres. Del feminismo a la política”. Recuperado de https://www.elmundo.es/elmundolibro/2001/11/14/anticuario/1005731836. html.

Daly, M. (1990): Gyn/ Ecology: The Metaethics of Radical Feminism. Beacon Press, Boston.

Doña, J. (1978): Desde la noche y la niebla: las mujeres en las cárceles franquistas. Ediciones de La Torre, Madrid.

Espinar Ruiz, E. (2003): Violencia de género y procesos de empobrecimiento (Tese doutoral), Universidade de Alicante, Alicante.

Fraser, N. (2013): Fortunes of feminism: from state - managed capitalism to neoliberal crisis. VersoBooks, Brooklyn, New York.

Gil Ruiz, J.M. (2014): "La violencia institucional de género", Anales de la cátedra Francisco Suárez,45, 9-16.

Gimeno, B. (2016): "Feminismo y neoliberalismo". Recuperado de https://beatrizgimeno.es/tag/neoliberalismo/.

Gimeno, B. (2016): “Feminismos en la sociedad neoliberal y heteropatriarcal”. Recuperado de https://beatrizgimeno.es/2016/05/19/feminismos-en-la-sociedad-neoliberal$\mathrm{y}$-heteropatriarcal/.

Grimaldos, A. (2013): Las claves de la Transición 1973-1986 (para adultos). De la muerte de Carrero Blanco al referéndum de la OTAN. Planeta de Libros, Barcelona.

Juliá Díaz, S. (2010): “Cosas que de la Transición se cuentan”, Ayer. Revista de Historia Contemporánea, 79, 297- 319. 
Kohan, M. (2018): "Duras críticas al Gobierno por romper el pacto de Estado contra la violencia de género", Público. Recuperado de https://www.publico.es/sociedad/ presupuestos-generales-duras-criticas-gobierno-romper-pacto-violencia-genero. html.

Larumbe, M.A. (2004): Las que dijeron que no. Palabra y acción del feminismo en la Transición. Prensas universitarias de Zaragoza, Zaragoza.

Martínez, E. (1997): "Políticas públicas para la igualdad entre los sexos: reflexiones sobre el caso español (1975-1997)" en Uriarte, E e Elizondo, A (eds.) Mujeres en política. Ariel, Barcelona.

McAdam, D, McCarthy, J e Zald, M. (1999): Movimientos sociales: perspectivas comparadas (Sandra Chaparro, trad.). Itsmo, Madrid (Obra orixinal publicada en 1996).

Millett, K. (1974): Flying. The New American Library (NAL), New York.

Montalbán, I. (2016): "Malos tratos, violencia doméstica y violencia de género desde el punto de vista jurídico", Revista electrónica de ciencia penal y criminología, 8 , $1-14$.

Morcillo, A. (2015): En cuerpo y alma: ser mujer en tiempos de Franco. Siglo XXI, Madrid.

Nash, M e Tavera, S (Eds.). (2003): Las mujeres y las guerras: el papel de las mujeres en las guerras de la Edad Antigua a la contemporánea. Icaria Editorial, Barcelona.

Pizzey, E. (1974): Scream Quietly or the Neighbours Will Hear. Pelican, London.

Platt, T. (1997): "La violencia como concepto descriptivo y polémico", Revista internacional de Ciencias Sociales, 132, 171-276.

Sádaba, I e Barranquero, A. (2019): "Las redes sociales del ciberfeminismo en España: identidad y repertorios de acción", Athenea Digital, 19 (1), 1-24.

San José, B. (1989): Democracia e igualdad de derechos laborales de la mujer: por un consenso social sobre la necesidad de una política contra la discriminación de las mujeres en el empleo. Instituto de la Mujer, Madrid.

Shiva, V. (1989): Staying Alive: Women, Ecology and Development. Zed Books Ltd, London. https://doi.org/10.1111/j.1527-2001.1991.tb00218.x

Tiganus, A. (2017): "La revuelta de las putas". Recuperado de https://feminicidio.net/ articulo/la-revuelta-las-putas.

VV.AA. (1963): La mujer en la nueva sociedad. Ediciones del Movimiento, Madrid.

Zelik, R. (2016): Continuidad o ruptura. Perspectivas de cambio en el Estado Español. Capitán Swing, Madrid. 